\title{
DE CULTURA A MERCANCÍA. LA CONFIGURACIÓN DE LA PROPIEDAD INTELECTUAL EN EL MARCO DE LA ORGANIZACIÓN MUNDIAL DEL COMERCIO
}

\author{
JOAN RAMOS TOLEDANO*
}

\section{INTRODUCCIÓN}

La propiedad intelectual, en su sentido más amplio (derechos de autor o copyright, patentes, marcas...), no puede entenderse hoy como el fruto de una decisión soberana e individual de un Estado para proteger e incentivar -si es que verdaderamente sirve para ello- la creación artística e intelectual en su territorio. En siglos pasados, en cambio, los derechos de autor y el copyright o los derechos de patentes de un país dependían de cómo quisiera regularlos ese país; por tanto, esos derechos eran relevantes en otra nación solo en la medida en que esta última quisiera reconocerlos. Por ejemplificar, una patente inglesa por la invención de un motor específico o el copyright sobre una novela fiaban su protección en Italia a que este país, soberano, tuviera la voluntad política de reconocer a extranjeros los mismos derechos que reconocía a sus nacionales.

Es decir, que, si bien el régimen de propiedad intelectual e industrial era aplicable, en principio, a todo un territorio nacional sin diferencias entre los ciudadanos, su eficacia internacional dependía de que los países llegaran a acuerdos entre ellos. Y durante un tiempo, la protección de obras y creaciones más allá de las fronteras del

* Licenciado en Derecho (2010). Máster en Ciudadanía y Derechos Humanos: Ética y Política, por la Universidad de Barcelona. Doctor cum laude por la Universidad de Barcelona (2017). Miembro del grupo de investigación "sGR371 - GRC Filosofía del derecho, moral y política" (Generalitat de Catalunya) y del Proyecto "La legitimidad de la gobernanza en tiempos de crisis: análisis del funcionamiento del Método Abierto de Coordinación (MAC) en España, Portugal e Italia de 2010 a 2015”, que cuenta con una subvención del Ministerio de Economía y Competitividad (DER2014-53891- P). Ha participado en un libro colectivo con dicho grupo de investigación (Estévez Araújo, José A. y Messina, Giovanni (eds.). La democracia en bancarrota. Madrid: Trotta, 2015), así como en diversos artículos y ponencias en congresos. Actualmente es investigador del Departamento de Ciencia Política, Derecho Constitucional y Filosofía del Derecho de la Universidad de Barcelona (España). Barcelona, España. Correo electrónico: jramostoledano@gmail.com. Fecha de recepción: 11 de agosto de 2017. Fecha de aceptación: 12 de octubre de 2017. Para citar el artículo: Ramos Toledano, J. "De cultura a mercancía. la configuración de la propiedad intelectual en el marco de la Organización Mundial del Comercio", Revista La Propiedad Inmaterial n. ${ }^{\circ} 24$, Universidad Externado de Colombia, julio-diciembre 2017, pp. 67-94. DoI: https://doi.org/10.18601/16571959.n24.04 
país de origen era una cuestión bastante incierta ${ }^{1}$. El régimen actual de propiedad intelectual e industrial, ampliamente uniformizado y homogeneizado durante los últimos 25 años, es, en este sentido, un hecho novedoso y excepcional en comparación con los últimos dos siglos. Pero este régimen internacional, en el que la Organización Mundial del Comercio (OMC) ha jugado un papel fundamental, no puede ser visto como la evolución natural de una progresiva internacionalización de la protección de la propiedad intelectual e industrial. Al contrario, ha sido fruto de intensas luchas entre intereses contrapuestos y entre diferentes formas de entender cómo deben gestionarse la creación intelectual y artística del ser humano y la transmisión del conocimiento entre generaciones.

Así pues, en la medida en que el mundo se encuentra cada vez más conectado - de forma sin igual, sobre todo en las últimas dos décadas, lo que ha venido a denominarse proceso de globalización-y los bienes, ideas, personas o mercancías circulan con mayor facilidad (las personas, sobre todo, si tienen escasos recursos, siempre encuentran mayores dificultades para circular), este reconocimiento de la propiedad intelectual e industrial a nivel internacional se ha convertido en un tema de importancia creciente en términos económicos, en especial desde el momento en que el conocimiento humano (obras artísticas, inventos y fórmulas, ecuaciones) es entendido cada vez más como una mercancía con la que puede comerciarse, como si fuera cualquier otro bien.

En el presente trabajo se analiza lo que se considera un verdadero orden institucional internacional que, sobre todo a partir de la creación de la omc, ha venido a trabajar por la protección y el reconocimiento internacionales de una concepción característica sobre cómo deben gestionarse las creaciones artísticas, los inventos y, en suma, gran parte del conocimiento. Esta concepción, como se ha dicho, considera que esos bienes inmateriales pueden comprenderse como mercancía cuyo tráfico debe ser protegido y asegurado, independientemente de las consecuencias que esta regulación tenga para los ciudadanos o los propios creadores.

Se defiende así, en lo que sigue, que tanto la omc como el llamado Acuerdo sobre los Aspectos de los Derechos de Propiedad Intelectual relacionados con el Comercio (ADPIC) han tenido como objetivo imponer esta visión mercantilista de la producción intelectual en todo el mundo, incluyendo la regulación legal que permite hacerla efectiva. Esta regulación, como se verá, favorece en particular a los países exportadores de este tipo de bienes (principalmente a EE. UU., la $\mathrm{UE}^{2}$ y Japón) y a grandes conglomerados empresariales, como productoras

1 A raíz de su independencia, y durante gran parte del siglo XIX, EE. UU. fue el principal país del mundo en piratería de libros. Todas las publicaciones británicas se imprimían en EE. UU. en ediciones de peor calidad y a bajo coste, sin pagar nada a sus propietarios en Reino Unido. Ello permitió que muchos ciudadanos americanos tuvieran acceso a muy bajo coste a gran cantidad de obras y, a su vez, el surgimiento de escritores americanos.

2 Resulta cuando menos curiosa la unidad de acción de la UE (antes CE) en la defensa de la propiedad intelectual, dada la dificultad que ha mostrado en muchos otros ámbitos para hablar con una sola voz. Vid. Malbon, Justin y Lawson, Charles. Interpreting and implementing the TRIPS Agreement. Is it fair? Cheltenham: Edward Elgar, 2008. ISBN: 9781847201447 . 
cinematográficas o empresas farmacéuticas. Se defiende también que, contrariamente a lo que afirma la propia omc, la normativa internacional no repercute de forma positiva en los países menos desarrollados (pobres). Al contrario, son estos los que asumen los costes de proteger las ideas, las creaciones artísticas y los inventos como si se trataran de mercancías. Dichos costes pueden suponer incluso vidas humanas, como sucedió con el virus del viH y las farmacéuticas en el continente africano.

La hipótesis de la que se parte es, pues, que el régimen internacional de propiedad intelectual e industrial no fomenta ni incentiva la creación o investigación, ni genera beneficios y riqueza para la mayoría de los países, sino solo para unos pocos a costa de los más pobres. Y para ello se utilizan instituciones internacionales como la OMC -pero también el Banco Mundial o el Fondo Monetario Internacional-, carentes de legitimidad democrática alguna, y presiones internacionales que en ocasiones suponen auténticos abusos a costa de la integridad y el desarrollo de las gentes. El régimen internacional de propiedad intelectual e industrial, en este sentido, resulta un claro ejemplo de la utilización por parte de poderosas organizaciones empresariales del entramado estatal, que se sirve de la influencia en diversos gobiernos para proteger sus intereses al margen de cualquier control democrático.

Este proceso ha mutado en los últimos años, pues la dificultad para adoptar decisiones en el seno de la omc ha llevado a distintos países a impulsar tratados bilaterales para imponer sus estándares de protección respecto a la propiedad intelectual e industrial. Más recientemente, las principales potencias económicas y comerciales del mundo han tratado de establecer pactos y tratados regionales para garantizarse zonas de influencia mercantil más amplias ${ }^{3}$. El presente trabajo trata de analizar en concreto el paso de la Organización Mundial de la Propiedad Intelectual a la Organización Mundial del Comercio, así como los esquemas de funcionamiento de esta. En este sentido, se analiza el paso de la OMPI a la OMC, porque supuso la aceptación implícita de regular unos bienes determinados -relacionados con expresiones artísticas, intelectuales, culturales y científicas, fundamentales para el desarrollo de las sociedades- como bienes mercantiles con los que comerciar, como si se trataran de cualquier otro bien.

Aunque este trabajo analiza lo que en derecho de tradición continental se denomina propiedad intelectual (derechos de autor, copyright), se atiende también parcialmente a lo que en los países de dicha tradición se denomina propiedad industrial (principalmente, aunque no solo, patentes y marcas), y ello porque a nivel internacional los Intellectual Property Rights (IPR) engloban ambos ámbitos y

3 Ramos Toledano, Joan. Bilateralidad, pérdida de soberanía y secretismo. En mientrastanto.e. Barcelona: Fundación Giulia Adinolfi-Manuel Sacristán. 2016, (146). ISSN (versión digital): 2014-7317. Disponible en http://www.mientrastanto.org/boletin-146/ notas/bilateralidad-perdida-de-soberania-y-secretismo 
su negociación e imposición se realizan conjuntamente (en el marco de la OMC y los ADPIC), sin distinción alguna.

\section{COMERCIO INTERNACIONAL EN EL MARCO DE LA OMC}

\section{I.I LA INTERNACIONALIZACIÓN DE LA PROPIEDAD SOBRE LOS BIENES INMATERIALES}

El reconocimiento de los derechos de propiedad intelectual por parte de un Estado para nacionales de otro Estado ha sido tradicionalmente una cuestión de voluntad política. El desarrollo de las primeras normas de propiedad intelectual en Europa afectaba por tanto a los Estados que las aprobaban, con especial relevancia de Francia y el Reino Unido, que encarnan los dos modelos principales: derechos de autor y copyright, respectivamente.

Los cambios tecnológicos y científicos a raíz de la Segunda Revolución Industrial contribuyeron definitivamente a mostrar la importancia que los bienes inmateriales podían tener en el desarrollo económico de un país y en un modelo de negocio hasta el momento testimonial. Fórmulas, escritos, composiciones musicales o inventos, así como fotografías y algo después el cine, aparecían no solo como elementos clave para el conocimiento, la educación y el desarrollo de una sociedad, sino como posibles bienes con los que comerciar y obtener importantes beneficios económicos. Si las sociedades incipientemente capitalistas de los siglos XVII y XVIII en Europa empezaron a regular las publicaciones de libros o algunas formas de patente por razón de las pequeñas formas de negocio que surgieron en torno a la edición y a nuevas invenciones, los siglos XIX y XX implicaron una apuesta clara por los bienes inmateriales como uno de los sectores clave de las economías más desarrolladas. Y, para ello, los Estados exportadores de esta clase de bienes inmateriales necesitaron que estos gozaran de un marco legal similar al suyo fuera de sus fronteras.

Así, más allá de los posibles acuerdos bilaterales entre naciones, el Convenio de París para la Protección de la Propiedad Industrial de 1883 y el Convenio de Berna para la Protección de las Obras Literarias y Artísticas de $1886^{4}$-ambos todavía vigentes, aunque superados en muchos aspectos por otros acuerdos- marcaron un hito importante en la historia de la protección internacional de la propiedad intelectual e industrial y supusieron la plasmación normativa de un modo de entender las creaciones inmateriales desde un punto de vista estrechamente relacionado con su

4 Estos dos convenios (así como otros 24) son gestionados por la Organización Mundial de la Propiedad Intelectual (OMPI, WIPO en sus siglas en inglés), organismo especializado perteneciente a Naciones Unidas. La creación de la Organización Mundial del Comercio y de los llamados ADpic (Acuerdo sobre los Aspectos de los Derechos de Propiedad Intelectual relacionados con el Comercio) en 1995 marcó un hito histórico al sustraer la gestión del conocimiento humano de un organismo como Naciones Unidas para insertarlo en un organismo internacional dedicado al comercio. 
comercialización, pues comprenden el conocimiento y ciertos elementos culturales como bienes susceptibles de ser objeto de negocio. Es más, esta normativa supone la internacionalización de una forma de entender la gestión y la transmisión de los bienes culturales que en Europa y EE. UU. se vio fuertemente condicionada por el auge de las economías capitalistas de libre mercado.

El éxito de esta forma de entender la regulación de los bienes culturales y las invenciones -en no pocas ocasiones derivado de una verdadera imposición, tanto mediante amenazas políticas como con sanciones comerciales o directamente la intervención militar (colonialismo)- ha provocado su expansión a sociedades muy diferentes a la europea o a la americana. En consecuencia, todas las otras formas de gestión del conocimiento y creación y transmisión de la cultura -no necesariamente mercantilistas, como es el caso de los aborígenes australianos ${ }^{5}$ o la sociedad japonesa ${ }^{6}$ precapitalista- han quedado sin reconocimiento oficial en el marco internacional.

Es decir, la normativa internacional en esta materia -que, como se verá, determina en gran medida la normativa nacional-impone una forma de entender la gestión del patrimonio cultural y tecnológico humano. Una forma cuyo principal objetivo es permitir la apropiación privada de ese patrimonio en forma de bienes comercializables para generar beneficios económicos, independientemente de las necesidades de la sociedad que posibilita esas mismas creaciones y de las condiciones de los propios creadores.

Durante la segunda mitad del siglo xx -y en parte ya durante la Segunda Guerra Mundial-se produjeron cambios sin precedentes en el ámbito de la informática, la química, la biotecnología, nuevos materiales, la robótica, la inteligencia artificial, etc., en definitiva, lo que ha venido a denominarse una Tercera Revolución Industrial ${ }^{7}$. Se produjo también una creciente mercantilización de algunos bienes culturales que se convirtieron en objeto de entretenimiento masivo, especialmente en el medio de la música, el cine y la literatura, así como una fuerte apuesta por expandir el ámbito de lo patentable, lo cual puso de manifiesto que los bienes inmateriales -que en realidad no son sino derechos de propiedad sobre creaciones intelectuales- pueden suponer una importante fuente de riqueza hasta tal punto de convertirse en una de las industrias más importantes para países como EE. UU., Japón y algunos Estados de la Unión Europea. El fin de la URss, la quiebra del keynesianismo y el avance definitivo del proceso de globalización a partir de los años noventa marcaron un antes y un después en las políticas de gestión de

5 Drahos, Peter. When cosmology meets property: Indigenous people's innovation and intellectual property. Prometheus: Critical Studies in Innovation. UK: Taylor and Francis, 2011, 29(3), pp. 233-252. IssN: 0810-9028.

6 Mitsui, Toru. Copyright and music in Japan: A forced grafting and its consequences. En S. Frith (ed.). Music and copyright. Edinburgh: Edinburgh University Press, 1993, pp. 125-145. ISBN: 0748604812.

7 Capella Hernández, Juan Ramón. Fruta prohibida. Una aproximación históricoteorética al estudio del derecho y del Estado. Madrid: Trotta, 2008. isBn: 978-84-9879-013-9. 
los bienes culturales y el inicio de una agresiva operación de expansión del modelo mercantilista que venía perfilándose ya desde el siglo XIX en Europa.

Los países ricos -en el ámbito de la propiedad industrial e intelectual suele hacerse referencia principalmente a EE. UU., Japón y la UE, pero también tienen cabida otros países, como Australia o Canadá-, exportadores netos de productos intelectuales como patentes, marcas, libros, música, películas, fotografía etc., trataron de poner en marcha durante la última década del siglo xx un mecanismo que garantizara en cualquier país del mundo el mismo régimen de protección para los bienes inmateriales que el suyo propio nacional. Solo así todo este haz de creaciones intelectuales podría producir para estos países exportadores -y directamente para las industrias que hay detrás- los máximos beneficios posibles. Para ello, la Organización Mundial del Comercio (омC) y el llamado Acuerdo sobre los Aspectos de los Derechos de Propiedad Intelectual relacionados con el Comercio (ADPIC, TRIPS en sus siglas en inglés) han resultado ser elementos fundamentales, indispensables para poder explicar la propiedad intelectual e industrial hoy en día ${ }^{8}$.

En la actualidad, el principal instrumento internacional que regula todo el ámbito de la propiedad intelectual e industrial de forma general es el Acuerdo de los ADPIC. Este se encuentra inserto en la OMC, por lo que la forma en que esta funciona afecta de manera determinante a la normativa sobre derechos de autor o patentes. Los ADPIC, por su lado, regulan un exigente sistema de mínimos sobre protección a la propiedad intelectual e industrial que deben adoptar en su normativa nacional todos los países miembros de la OMC. Los incrementos de protección que se han dado en la última década han sido sobre todo por medio de mecanismos bilaterales o de ámbitos regionales (como en la UE). Los ADPIC, entonces, permanecen como el elemento normativo internacional más importante y extendido en esta materia, tanto por la estructura en la cual están insertos -la Organización Mundial del Comercio- como por el alcance que han logrado.

\section{I.2 El PASO DE LA PROPIEDAd INTELECTUAL E INDUSTRIAL A LA OMC Y EL FUNCIONAMIENTO DESIGUAL DE LA ORGANIZACIÓN}

La lógica de funcionamiento del régimen internacional actual de propiedad intelectual e industrial no puede explicarse sin dar cuenta de cómo la OMC adopta sus decisiones, y ello porque, a raíz de su creación en 1995, esta organización se ha convertido en el verdadero marco desde el cual se ha impulsado la normativa en esta materia: los ADPIC.

En 1947, tras la Segunda Guerra Mundial, veintitrés países (entre ellos los vencedores de la guerra, como EE. UU., Francia o el Reino Unido) firmaron un acuerdo conocido como GaTt o General Agreement on Tariffs and Trade (Acuerdo

8 Dinwoodie, Graeme y Dreyfuss, Rochelle. A neofederalist vision of trips. The resilience of the International Intellectual Property Regime. New York: Oxford University Press, 2012. ISBN: 9780195304619. 
General sobre Aranceles Aduaneros y Comercio). Por ser uno de los objetivos principales de este Acuerdo potenciar las relaciones comerciales libres de aranceles o protecciones (libre comercio), solo se adhirieron los países del bloque occidental, más proclives a adoptar una economía capitalista de mercado. Aunque el Acuerdo no preveía la creación de ninguna institución permanente, se estableció una organización en Ginebra con estructura administrativa, representación permanente y espacio físico para que los delegados pudieran trabajar en un lugar fijo más allá de las reuniones periódicas bianuales.

En un principio, el GATT pretendía permitir a los Estados miembros un fácil diálogo para la adopción de medidas tendentes a reducir aranceles y el librecambio internacional. El modo más importante en el que se adoptaban decisiones-marco eran las rondas de negociación multilaterales encaminadas a liberalizar el comercio internacional ${ }^{9}$. En 1994, en el marco de la octava ronda (conocida como Ronda de Uruguay), los Estados parte del GATT decidieron crear la OMC como organismo encargado de fomentar la liberalización de los intercambios internacionales ${ }^{10}$. Así, por medio del conocido Acuerdo de Marrakech, nació la Organización Mundial del Comercio.

El Acuerdo también contenía cuatro grandes anexos. El primero estaba dividido, a su vez, en tres subanexos: el 1A, que recogía un nuevo GATT, así como otros acuerdos (de agricultura, textil o subvenciones, entre otros); el 1B, que recogía el GaTs o General Agreement of Trade and Services; y el 1C, que recogía los ADPIC, relativos a la propiedad intelectual e industrial. El segundo anexo preveía las normas y los procedimientos para la solución de diferencias entre Estados respecto de la aplicación del Acuerdo. El tercer anexo versaba sobre el Mecanismo de Examen de las Políticas Comerciales, y finalmente el cuarto preveía acuerdos comerciales plurilaterales sobre temas sectoriales, por ejemplo, contratación pública o comercio de aeronaves civiles.

Los ADPIC, pues, han formado parte fundamental de la OMC desde el momento mismo de su creación. Como se verá, los principales beneficiados de los ADPIC (y de la OMC) son los países desarrollados -eminentemente EE. UU., que impulsó su inserción en el marco de la OMC, y la UE, que presentó la propuesta final del texto, a la postre aprobado-. Como se verá también, el hecho de que los ADPIC hayan quedado bajo el paraguas de la OMC y no ya bajo la regulación de la Organización Mundial de la Propiedad Intelectual no ha sido ni casual ni inocente.

9 Díez de Velasco, Manuel. Las organizaciones internacionales. 14. ${ }^{a}$ ed. Madrid: Tecnos, 2006, pp. 440 y ss. ISBN: 9788430942978.

$10 \mathrm{La}$ омc es una clara continuación de lo que había venido realizando el GATT. No obstante, la OMC cuenta con una infraestructura y un número mucho mayor de Estados parte. Esta expansión del modelo económico propugnado por la OMC (que pasa de ser un acuerdo multilateral a englobar, en unos años, a casi todos los países del mundo) se debe, en parte, al fin de la alternativa que suponía el bloque soviético. 


\subsubsection{De la OMPI a la OMC}

La OMC trabaja, en principio, en colaboración con la Organización Mundial de la Propiedad Intelectual (OMPI, WIPO en sus siglas en inglés), respetando los tratados y convenios ya existentes que esta gestiona, como los ya mencionados de París y de Berna. En este sentido, el Acuerdo de los ADPIC supone una novedad porque implica la asunción de la gestión y la transmisión de formas de conocimiento y cultura humanas por parte de una organización cuyos objetivos están relacionados con el comercio. Este "salto de la OMPI a la OMC"11 refuerza por tanto la percepción de que los bienes culturales pueden ser considerados como una mercancía más. La idea subyacente es que las obras artísticas o culturales y los inventos y desarrollos tecnológicos pueden y deben ser apropiados y comercializados privadamente y que, por tanto, su tráfico jurídico debe ser regulado, ha de estar protegido y asegurado -debe ser previsible para dar seguridad jurídica a quienes comercian con estos bienes-.

Las excepciones a las normas impuestas por los ADPIC (como la llamada "excepción cultural" en Francia, que permite imponer cuotas de cine francés en sus salas, o las excepciones a las patentes por motivos de salud pública) son escasas y en ocasiones con muchos obstáculos para que los países puedan esgrimirlas. Ciertos Estados - particularmente EE. UU. y algunos países europeos- presionan duramente a aquellos que tratan de buscar excepciones a las normas de propiedad intelectual e industrial impuestas por los ADPIC y la OMC que alivien la situación de sus ciudadanos, tanto en temas educativos como, sobre todo, en ámbitos de salud.

La inclusión de los ámbitos de propiedad intelectual e industrial bajo el paraguas de una organización comercial implica que, en los debates de la OMC sobre estos temas, la decisión última provenga de un cargo político cuyas responsabilidades son de carácter comercial, industrial y económico. Al margen de que cada país cuente con expertos en determinadas materias sometidas a debate en el seno de la OMC (por ejemplo, expertos en agricultura, en servicios de transporte o en aviación civil), en última instancia, los delegados en Ginebra para las reuniones forman parte del Ministerio de Comercio -o equivalente en cada Estado- y no del Ministerio de Salud o Educación, dos ámbitos enormemente afectados por lo que se decida acerca de la propiedad industrial e intelectual ${ }^{12}$.

A pesar de cierta reticencia inicial por parte de algunos países en desarrollo y países pobres de permitir este paso de la propiedad intelectual e industrial de la OMPI a la OMC por medio de los ADPIC, lo cierto es que los principales impulsores de este cambio (EE. UU., Europa y Japón) no encontraron grandes resistencias, ello pese a que se trata de un salto cualitativo para el que difícilmente hay marcha

11 Smiers, Joost. Un mundo sin copyright. Artes y medios en la globalización. Barcelona: Gedisa, 2006, p. 236. ISBN: 978-84-9784-052-1.

12 Jawara, Fatoumata y Kwa, Aileen. Tras las bambalinas de la omc. La cruda realidad del comercio internacional. Barcelona: Intermón Oxfam Editorial, 2005. ISBN: 9788484523246. 
atrás ${ }^{13}$. Parte de esta facilidad para incluir la propiedad intelectual e industrial como elemento de comercio bajo la estructura de la OMC se ha debido a la concesión de los Estados ricos a los pobres de ciertas ventajas económicas en otros ámbitos, como "incrementar el acceso al mercado textil o el compromiso de futuras liberalizaciones en la agricultura" ${ }^{\prime \prime}$, es decir, prometiendo un incremento del acceso de ciertos productos (por ejemplo, de países africanos) a los mercados europeo y estadounidense, promesas muchas veces incumplidas o postergadas durante décadas.

En el análisis de cómo la propiedad intelectual e industrial pasó de la OMPI a la OMC, subyace la idea constante de que los países menos desarrollados no comprendían el potencial de ese cambio. Es decir, que los países pobres -inexpertos muchas veces en temas de propiedad intelectual o industrial, sea por la escasez de creación tecnológica y cultural, sea porque gestionaban de otra forma menos comercial el conocimiento de su sociedad- no eran del todo conscientes de lo que iba a suponer aprobar el Acuerdo de los ADPIC y el impacto que ello podría tener en sus economías y en sectores como el de la salud o la educación. Es difícil imaginar que, de haberlo sabido, muchos países pobres no hubieran ofrecido mayor resistencia a una normativa que permite patentar recursos biológicos (sustrayendo su uso a los pueblos que tradicionalmente han utilizado esos recursos), que vuelve inaccesibles para los ciudadanos muchos medicamentos vitales o que dificulta el acceso a bienes culturales porque se encuentran dominados por grandes industrias internacionales del entretenimiento.

El principal interés en vincular la propiedad intelectual e industrial a la omc era, pues, de los países exportadores de estos bienes inmateriales considerados como mercancía, particularmente de EE. UU., cuya industria cinematográfica, farmacéutica e informática presionó durante los años ochenta para vincular este ámbito al comercio internacional. Para ello, algunas de estas grandes industrias formaron el ACTN (Advisory Comittee for Trade Negotiations), integrado por directivos de empresas del sector (IвM, DuPont, Pfizer), con la tarea de proporcionar asesoramiento al US Trade Representative ${ }^{15}$, que participaba en las negociaciones internacionales ${ }^{16}$.

El paso a la OMC implica además la posibilidad por parte de los Estados miembros de utilizar el mecanismo de resolución de conflictos previsto en el GATT contra

13 Sell, Susan. Life after trips - Aggression and opposition. En K. Maskus (ed.). The WTO, intellectual property rights and the knowledge of economy. Cheltenham: Edward Elgar, 2004, pp. 72-119. IsBN: 9781843762379.

14 Maskus, Кегтн. Regulatory standards in the wто: Comparing intellectual property rights with competition policy, environmental protection, and core labor standards. En K. Maskus (ed.) The WTO, intellectual property rights and the knowledge of economy. Cheltenham, Edward Elgar, 2004. IsBN: 9781843762379. Ibid., pp. 56-57.

15 La ustr (US Trade Representative) Office u Oficina del Representante de Comercio de EE. UU. es la agencia estadounidense encargada de planificar y desarrollar la política comercial de este país. Su cercanía a sectores empresariales e industriales privados es una constante con todos los gobiernos de EE. UU.

16 Drahos, Peter. Information feudalism in the information society. The Information Society. U. S. A.: Taylor and Francis, 1995, 11(3), p. 212. ISSN: 0197-2243. 
otros países si consideran que no se cumplen las exigencias previstas en el Acuerdo de los ADPIC. Entre las posibles consecuencias están las sanciones comerciales ${ }^{17}$, que en última instancia pueden repercutir en la población, una población que en algunos casos ya vive en condiciones cuando menos de dificultad. Por si fuera poco, la entrada en la OMC exige la aceptación por parte de los nuevos Estados de todos los acuerdos y tratados aprobados en su seno, incluidos los ADPIC.

Las sanciones tienen efectos muy diferentes para los distintos países, es decir, no es lo mismo que EE. UU. imponga restricciones comerciales a un país asiático o surafricano que a la inversa. De hecho, para los países pobres puede resultar incluso contraproducente castigar a un país incumplidor, pues le supone mayor costo económico a aquel que al sancionado.

\subsubsection{Negociaciones, amenazas, pactos y promesas}

Este paso de la OMPI a la OMC, por tanto, ha implicado someter la propiedad intelectual e industrial a las formas de funcionar y adoptar decisiones de la OMC, que, como ha ido quedando patente con el paso de los años, resultan especialmente desiguales y perjudiciales para los países subdesarrollados.

La Organización Mundial del Comercio celebra sus principales reuniones, las Conferencias Ministeriales (Seattle, 1999; Doha, 2001), cada dos años. En estas reuniones participan todos los países miembros $(164)^{18}$ y cada Estado cuenta con un voto. Las Conferencias Ministeriales son importantes porque en ellas se toman las principales decisiones de la Organización. Ahora bien, la necesidad de consenso entre todos los miembros -forma heredada de las antiguas reuniones del GATTprovoca un juego de poderes en el que las negociaciones, las amenazas, los pactos y las promesas son elementos cotidianos. Esto ocurre porque, dado el tamaño actual de la omc (casi todos los países del mundo), la unanimidad no resulta ser la forma adecuada de tomar decisiones, máxime cuando las decisiones que favorecen a unos tienden a perjudicar a otros. Así pues, al margen de la postura oficial de la Organización -bajo la cual las decisiones se toman de forma unánime-, el funcionamiento real se basa en (y provoca) profundas desigualdades entre sus miembros a la hora de obtener resoluciones favorables a sus intereses.

Si se piensa en la propia estructura de la OMC, en sus objetivos (claramente económico-comerciales) y en la adopción de decisiones por unanimidad, cabe formular las siguientes preguntas: ¿`cómo puede una organización cuyos miembros tienen en muchas ocasiones intereses contrapuestos e incompatibles satisfacer las necesidades de todos ellos? ¿Funciona la OMC de forma que todos los Estados ce-

17 Harris, Donald. Trips' rebound: An historical analysis of how the trips Agreement can ricochet back against the United States. Northwestern Journal of International Law \& Business. Chicago: Northwestern University, 2004, 25(1), pp. 99-163. Issn: 0196-3228.

18 A 29 de agosto de 2017, son 164 los miembros de la omc según la propia organización: https://www.wto.org/spanish/thewto_s/whatis_s/tif_s/org6_s.htm 
den en algunos aspectos a la hora de tomar decisiones, de forma que todos salen equitativamente perjudicados o beneficiados? Resulta obvio que la adopción de ciertas decisiones (como proteger ciertos productos europeos con aranceles) puede perjudicar claramente a algunos países (la protección de productos europeos puede perjudicar las exportaciones de productos manufacturados africanos) en beneficio de otros. Luego, si la OMC adopta una decisión respecto a la protección arancelaria, esta puede beneficiar a uno en perjuicio de otros, pero aun así deberá ser tomada con el voto favorable de todos los Estados, incluidos aquellos que salen claramente perjudicados por la decisión.

Todo ello conlleva que, en realidad, una parte importante de las decisiones de la OMC sea cómo se negocian y se pactan antes de ser aprobadas por unanimidad, pues esa unanimidad no necesariamente implica que haya acuerdo sobre el tema ${ }^{19}$. Las negociaciones previas entre los diferentes países miembros resultan entonces de sumo interés, un campo en el que los países ricos han jugado con enorme ventaja. A ello han contribuido el hecho de que los tiempos juegan a favor de unos y en contra de otros, la diferencia de recursos entre países desarrollados y países pobres o la posibilidad de imponer sanciones de aquellos frente a estos.

El tiempo, en efecto, es un elemento a favor de los países desarrollados, que pueden sencillamente esperar a que el desgaste haga mella en los países pobres, en parte porque los países ricos no acostumbran a tener situaciones de urgencia nacional en materias como la salud pública. "Cuanto más tiempo hay, mejor pueden trabajar EE. UU. y la CE con los países en desarrollo y ejercer sus presiones unilaterales [...] En cierto modo, se instala el cansancio, [...] se cede más de lo que se hubiera cedido al principio" ${ }^{20}$. Además, aunque los países pobres sean más, numéricamente hablando, deben oponerse públicamente a lo que proponen los países ricos y poderosos. En ocasiones, la presión política es excesiva ${ }^{21}$.

También los recursos de los países desarrollados son considerablemente mayores. Ello permite a países como EE. UU., la UE o Japón tener más delegados en Ginebra o contratar asesoramientos legales, técnicos y económicos especializados. En ámbitos como los ADPIC, que recogen una forma de entender la gestión cultural con origen en Europa, este tipo de recursos y asesoramiento resulta fundamental para países cuya tradición en la gestión del conocimiento difiere mucho de la propiedad intelectual e industrial.

Es el caso de muchos países africanos, para los que gran parte de este tipo de regulación ha llegado impuesta por la colonización, o de países como Australia, cuyos aborígenes son creadores de obras y diseños, pero cuya gestión de ese conocimiento difiere totalmente del uso mercantil que hace el Gobierno australiano

19 Aunque se aprueben por unanimidad, en las decisiones de la omc acostumbra a haber claros ganadores y perdedores.

20 Jawara y Kwa. Op. cit., p. 56.

21 Drahos, Peter. When the weak bargain with the strong: Negotiations in the wto. International Negotiation. Leiden, The Netherlands: Brill, 2003, 8(1), pp. 77-109. ISSN: 1382-340X. 
de las creaciones intelectuales ${ }^{22}$ (en consonancia con la normativa internacional). Incluso Japón, para cuya sociedad la propiedad intelectual resultaba un elemento extraño, ha debido adaptarse a los imperativos internacionales, si bien cuenta con unas posibilidades de asesoramiento, una posición en la industria electrónica y una capacidad de presión lobbistica mucho mayores que han convertido al país nipón en una potencia en exportaciones de patentes y marcas ${ }^{23}$.

Así pues, no resulta extraño que, en el marco del Acuerdo de los ADPIC y la salud pública, por ejemplo -ámbito de importancia y sumamente técnico-, hubiera quejas en el seno de la omc por parte de los delegados de los países menos desarrollados al verse desbordados por la capacidad legal de los países ricos. Esta diferencia se ve aumentada por el hecho de que las principales empresas - del sector farmacéutico, por ejemplo- ponen sus recursos y sus amplios conocimientos técnicos al servicio de los países más desarrollados, a los que presionan para que defiendan sus intereses comerciales ${ }^{24}$.

El tiempo de las negociaciones o la ingente diferencia de recursos técnicos entre países ricos y países pobres son dos de las estrategias extraoficiales que inclinan la balanza a la hora de negociar y proporcionan a los países desarrollados una ventaja que permite explicar por qué, a pesar de tomarse las decisiones de forma unánime y haber más países pobres que ricos, estos salen comúnmente beneficiados por las medidas adoptadas. Y no son las únicas estrategias. También la propia estructura de la OMC contribuye a dar ventaja a los países desarrollados, concretamente por la forma como se resuelven los problemas que surgen entre distintos países respecto del cumplimiento de la normativa aprobada.

El sistema de resolución de conflictos de la OMC resulta claramente desigual y en no pocas ocasiones de escasa utilidad para los países pobres. Ello se debe, principalmente, a que una de las posibles $-\mathrm{y}$ a priori más efectivas- medidas por tomar a modo de castigo la conforman las sanciones comerciales sobre los países incumplidores, lo cual resulta enormemente asimétrico, dado que la restricción del tráfico comercial por parte de un país pobre hacia uno rico apenas repercute en la economía de este último, pero puede suponer una verdadera carga para el país menos desarrollado. Pero lo contrario -restricción comercial de EE. UU. a Tailandia, por ejemplo- se convierte en una medida poderosa y eficaz, capaz de lograr que los países pobres cumplan todos los acuerdos adoptados por la OMC (aun cuando estos les perjudiquen) y que desistan de persuadir a los países ricos de que a su vez cumplan bajo la amenaza de sanciones ${ }^{25}$.

Es más, los mismos delegados de los países en desarrollo reconocen que en ocasiones ni siquiera merece la pena emprender un litigio, "pues hay que seguir un proceso muy largo y caro. Aunque [...] contamos con el Centro Independiente

22 Drahos. When cosmology meets property...

23 Mitsui. Op. cit.

24 Jawara y Kwa. Op. cit. p. 144.

25 Ibid., p. 89. 
de Asesoría Legal en Asuntos de la OMC, nos sigue resultando mucho más práctico llegar a acuerdos al margen de los tribunales"26. De hecho, muchas de las disputas de la OMC se resuelven out of court, lo que permite a los países poderosos ejercer presión a los países más pequeños y conseguir que acepten su interpretación de un acuerdo o tratado en disputa $^{27}$.

$\mathrm{Si}$, a pesar de todo lo visto anteriormente, los países ricos se ven sobrepasados en número e incapaces de convencer al resto de los Estados, pueden sencillamente optar por no llegar a ningún acuerdo en el marco de la omc. Al adoptarse las decisiones de las Conferencias Ministeriales por unanimidad, es suficiente con que un país se niegue a aprobar la propuesta para que esta no salga adelante. Como se ha dicho, el tiempo juega en contra de los países pobres, cuyas poblaciones se encuentran generalmente en situaciones mucho más precarias, por lo que sus gobiernos observan con mayor urgencia posibles medidas que pueden suponer un incremento de las relaciones comerciales o una suavización de las exigencias. Por su parte, los países desarrollados pueden renunciar a llegar a acuerdos mediante la omC e intentar alcanzar sus objetivos por medio de otros mecanismos, lo cual, de hecho, es una práctica habitual.

Que las negociaciones queden encalladas no es infrecuente. En la Conferencia Ministerial de Cancún, ante la falta de acuerdo, el vicepresidente para Asuntos Económicos Internacionales de la National Association of Manufacterers de EE. UU. comentaba: "La industria estadounidense quiere acceso al mercado. Si no podemos conseguir un terreno de juego parejo en la OMC, sacaremos nuestras fichas de póquer de esta partida y empezaremos a negociar acuerdos de libre comercio donde sepamos que podemos lograr un trato justo"28. En realidad, y como se verá posteriormente con los ADPIC y la propiedad intelectual e industrial, en no pocas ocasiones a ciertos países desarrollados como EE. UU. o la UE les merece la pena tratar de conseguir sus objetivos mediante tratados bilaterales de libre comercio en los que acostumbran a conseguir imponer su criterio debido al temor político y económico que infunden estos países poderosos, cuyos castigos comerciales -cuando no militares- pueden perjudicar mucho a las poblaciones de los países pequeños (como los efectos del embargo comercial a Cuba).

Ante la desigual situación de los países ricos y los países pobres en el seno de la OMC, estos últimos han intentado establecer alianzas y pactos para tratar de ganar fuerza frente a gigantes como EE. UU., la UE, Japón o Canadá. Y la respuesta de los países ricos ha sido tratar de romper estas alianzas y provocar la división entre los Estados subdesarrollados. Las estrategias de división han sido varias y diferentes, y pueden consistir en simples y burdas amenazas, pero que, junto con el miedo de posibles sanciones y restricciones comerciales, terminan surtiendo efecto. En 
estos términos se expresaba el comisario de Agricultura de la CE sobre el G2029: "Cuando se mira la reciente propuesta extremista auspiciada por países como Brasil, China y la India, entre otros, no puedo evitar pensar que estamos en órbitas completamente diferentes. Si queremos trabajar, deben tener los pies en la tierra. Si quieren seguir en su órbita espacial, no llegarán a la luna ni a las estrellas, sino que más bien se irán con las manos vacías"30 .

EE. UU., por su parte, intentó sembrar cierta discordia para evitar que los países africanos se unieran al G20. Dos meses antes de la Conferencia Ministerial de Cancún, el presidente Bush había visitado al presidente de Uganda, Yoweri Museveni. Posteriormente, Museveni envió una carta a los ministros africanos advirtiéndoles de los peligros de alinearse con los países pobres asiáticos y latinoamericanos (G20) para los intereses de África, carta "cuya semejanza de estilo y contenido con la de Rosa Whitaker, antigua asistente del USTR [...] es demasiado sorprendente para que sea una coincidencia" ${ }^{31}$.

Estas dos últimas estrategias apuntadas -la consecución de objetivos mediante tratados bilaterales de libre comercio y los intentos de separar el G20- han sido incluso utilizadas simultáneamente. El senador estadounidense Chuck Grassley lanzó una amenaza velada en este sentido durante la Conferencia Ministerial de Cancún, avisando que utilizaría su posición política al pactar acuerdos bilaterales -que deben pasar por el Senado- teniendo en cuenta las posturas adoptadas por los miembros de la omc. Dijo literalmente que "los Estados Unidos evalúan posibles socios con los cuales establecer tratados de libre comercio sobre una base continua. Tomaré nota de las naciones que tuvieron un papel constructivo en Cancún y de las que no lo tuvieron" 32 .

Este tipo de amenazas tienen enormes repercusiones en países cuyas economías -y a veces la subsistencia de sus ciudadanos- dependen mucho de las relaciones comerciales internacionales. Este y otros avisos de EE. UU. o la UE tras la Conferencia de Cancún influyeron definitivamente en que Honduras y República Dominicana se mantuvieran fuera del G20 y de que El Salvador abandonara el grupo. Estados Unidos también advirtió que el cafta (Tratado de Libre Comercio entre EE. UU., Centroamérica y República Dominicana) era incompatible con pertenecer al G20. Tras una subvención de más de 6 millones de dólares a los socios del CAFTA, Costa Rica también se retiró del G20. El senador de EE. UU. Norm Coleman visitó Colombia tras la fallida Conferencia Ministerial de Cancún y le

29 El G20 o Grupo de Países en Desarrollo es un grupo de naciones en desarrollo -en torno a los 20 países, aunque su composición ha variado mucho a lo largo de los añosformado en la Conferencia Ministerial de Cancún (2003) para unificar ciertos intereses de los países pobres o en desarrollo frente a lo que consideraban ciertos abusos de los países ricos. En este sentido, supuso un claro contrapoder a EE. UU. y la UE en la OMC. Entre otros, forman este grupo China, la India, Argentina, Brasil, México, Sudáfrica y Venezuela.

30 Ibid., p. 38.

31 Ibid.

32 Ibid., p. 58. 
advirtió que seguir en el G20 no conduciría a buenas relaciones entre EE. UU. y Colombia. Poco después este último abandonó el G20 y efectivamente en 2004 se iniciaron las relaciones para un tratado de libre comercio con EE. UU. También terminaron abandonando el G20 Perú y Ecuador, y muchos otros se alejaron o condicionaron su pertenencia a la negociación solo en ciertos sectores o ámbitos, como en los casos de México y Tailandia.

En definitiva, el funcionamiento de la omc dista de ser abierto, transparente y democrático. La presión y las amenazas por parte de los países más ricos -especialmente de EE. UU. y la UE- son una constante y permiten explicar por qué la OMC adopta decisiones de forma recurrente que perjudican a la mayoría de sus miembros. Tal y como está configurada hoy en día, la OMC supone una suerte de estructura internacional cuyas decisiones (incluyendo las sanciones) van encaminadas a proteger los intereses comerciales de los países desarrollados, altamente representativos de los intereses de grandes empresas multinacionales. Esta forma de funcionamiento resulta de aplicación a todos los ámbitos que cubre la OMC, por consiguiente, también a los ADPIC y a las normas de propiedad intelectual e industrial.

A la luz del verdadero funcionamiento de la OMC en la adopción de decisiones, la Organización merece ser puesta en cuestión dado que falla en la consecución de sus objetivos básicos (en sus propias palabras, ser más beneficiosa para los paises en desarrollo o ser previsible y transparente ${ }^{33}$ ). La OMC, que juega un papel fundamental en la dirección de las políticas y la adopción de normativas de muchos países, forma parte de lo que J.R. Capella ha denominado soberano supraestatal difuso ${ }^{34}$, por cuanto goza de una enorme influencia internacional y toma decisiones que afectan a ciudadanos de todo el mundo, pero no se encuentra sujeta a control democrático ni transparencia alguna. Este nuevo "campo de poder" 35 cuenta con el apoyo de otras instituciones, como el Banco Mundial o el Fondo Monetario Internacional, que ofrecen créditos y facilidades económicas a los países en desarrollo si llegan a acuerdos -que generalmente les perjudican- en el seno de la OMC, plegándose a las peticiones de los países ricos ${ }^{36}$. En no pocas ocasiones, sin embargo, los países pobres se niegan a endeudarse bajo las condiciones de estos dos organismos, pues ello supone renunciar a una fuente de ingresos constante (debida a intercambios comerciales) a cambio de un préstamo puntual que va en detrimento de la economía del país a medio y largo plazo.

Lo que se ha visto hasta ahora es un esbozo de los modos de funcionar que tiene la OMC actualmente. Es en esta estructura internacional en la que se insertan como eje fundamental los ADPIC. Ello permite entender en qué marco funcionan

33 Ver https://www.wto.org/spanish/thewto_s/whatis_s/what_stand_for_s.htm, consultado el 29 de agosto de 2017.

34 Capella Hernández, Juan Ramón. Entrada en la barbarie. Madrid: Trotta, 2007, pp. 167 y ss. ISBN: 978-84-8164-779-2.

35 Capella. Fruta prohibida, p. 304.

36 Jawara y Kwa, Op. cit., p. 45. 
los derechos de propiedad intelectual e industrial y permite explicar con mayor facilidad cómo una normativa que perjudica los intereses de una gran mayoría de países en beneficio de unos pocos ha sido aprobada y en muchos casos es efectivamente aplicada por los países pobres.

\section{LA CONFIGURACIÓN INTERNACIONAL DE LOS ADPIC}

Como se ha visto, el Acuerdo sobre los Aspectos de los Derechos de Propiedad Intelectual relacionados con el Comercio (ADPIC) es una parte fundamental de la oMc. La inclusión de este anexo en el acuerdo constitutivo de la organización ha implicado valorar la propiedad intelectual e industrial como un aspecto más del comercio y someter la negociación de temas relacionados a los modos de funcionar -profundamente desequilibrados entre países ricos y pobres- de la омc.

En realidad, la propia idea de propiedad intelectual e industrial resulta en esencia contraria a la lógica de libre mercado en la que se basa la OMC. La propiedad sobre bienes inmateriales es una ficción que otorga un privilegio de monopolio temporal que trata de justificarse a sí mismo alegando que de esa manera (convertido en un bien intercambiable, en una mercancía) puede funcionar como activo económico y ser objeto de tráfico comercial, incentivando así la creación y repercutiendo en los beneficios de los creadores. La propiedad intelectual e industrial supone, por tanto, una excepción -en la lógica económica imperante- a los principios básicos de funcionamiento del capitalismo contemporáneo y la idea de libre comercio y libre competencia de la omc. En realidad, no obstante, es un privilegio que descansa sobre la imposición de una desventaja común en el acceso de la población al bien protegido ${ }^{37}$.

La propiedad intelectual e industrial, pues, supone una barrera al comercio, aunque en las negociaciones de la Ronda de Uruguay sobre la creación de la OMC "fue justificada $[. .$.$] como necesaria y favorable al comercio"38. Como argumenta$ Susan Frankel, que esto sea así es una opinión que fue discutida entonces y que todavía hoy lo es.

En lo que sigue, se defiende que la normativa internacional sobre propiedad intelectual e industrial, sobre todo por medio de los ADPIC, resulta económicamente proteccionista de un mercado (en particular, del estadounidense, pero también del europeo, del japonés y de ciertos países desarrollados) y que la normativa impone una suerte de libre mercado (en la medida en que prohíbe medidas de proteccionismo estatal) para una figura jurídica (la propiedad sobre bienes inmateriales) que es de por sí una ficción solo posible a partir de su creación, defensa y protección por parte del aparato estatal. De hecho, que los ADPIC suponen beneficios económicos

37 Drahos. Information feudalism..., p. 220.

38 Frankel, Susan. Legitimidad y finalidad de los capítulos de propiedad intelectual en los tratados de libre comercio (TLC). Revista La Propiedad Inmaterial. Bogotá: Universidad Externado de Colombia, 2011, (15), p. 178. ISSN: 1657-1959. 
para EE. UU., la UE o Japón es una evidencia constatable empíricamente, pero ello no implica necesariamente un beneficio para el comercio en general ${ }^{39}$. Al contrario, se puede argumentar -como se pretende aquí- que los ADPIC imponen un régimen altamente beneficioso para algunos países (ricos) en detrimento de otros, en clara consonancia con la forma como viene funcionando la OMC.

La historia de los ADPIC es en definitiva la historia sobre cómo determinados países han conseguido adaptar la legislación internacional -que a su vez configura la normativa nacional de cada Estado- a sus intereses comerciales, con la consecuencia de que se ha sustraído a las poblaciones la capacidad de decidir de forma democrática sobre aspectos de importancia comercial y económica que afectan a la gestión del conocimiento y las expresiones artísticas y culturales de la sociedad.

Pero la aprobación del Acuerdo de los ADPIC no ha sido del todo pacífica, por más que el carácter unánime de la OMC así pudiera sugerirlo y aunque, en última instancia, los países en desarrollo no consiguieran oponerse de forma efectiva. Durante las negociaciones de la Ronda de Uruguay del GATT (de donde acabaría saliendo la OMC) en 1994, los principales Estados promotores de un acuerdo sobre propiedad intelectual e industrial -lo que serían finalmente los ADPIC- fueron EE. UU., la UE, Japón y Canadá (grupo conocido como Quad) ${ }^{40}$. No obstante, existía cierta oposición -liderada por países como la India, Brasil o Argentina- a regular la propiedad intelectual e industrial en el marco del GATT, ámbito eminentemente comercial.

Estos Estados habían conseguido oponerse a un aumento excesivo de protección de los bienes inmateriales de forma efectiva en ámbitos como la OMPI, pero, en última instancia, fueron incapaces de frenar la aprobación de los ADPIC. Una de las estrategias utilizadas por el Quad fue la promesa de que el Acuerdo mejoraría la economía de todos los países del mundo, lo cual se ha demostrado claramente falso. Pero, sin duda, uno de los argumentos más efectivos fue el de proponer (pequeños) beneficios comerciales - como la apertura de los mercados estadounidense o europeo a ciertos productos africanos o latinoamericanos- a cambio del apoyo de los países pobres. A la hora de la verdad, los países ricos han retrasado constantemente la aprobación de estos beneficios comerciales, que no han tenido apenas impacto en las economías de los países pobres.

También posteriormente, con el Acuerdo ya aprobado, ha habido cierta oposición - una vez se han ido viendo las consecuencias-, particularmente en cuanto a las patentes de ciertas formas de vida y a las patentes farmacéuticas ${ }^{41}$. Otros ámbitos, como el copyright o los derechos de autor, han quedado al margen -en general- de esta oposición estatal, circunscribiéndose a movimientos alternativos estrechamente relacionados con Internet y las licencias Creative Commons. La resistencia ofrecida $-\mathrm{y}$ las victorias obtenidas, como las relacionadas con los medicamentos 
y las licencias obligatorias (Doha, Seattle)- muestra que la omc, en general, y los ADPIC, en particular, no cuentan ni por asomo con la unanimidad con la que fueron aprobados. La poco efectiva oposición antes de su aprobación se debe, en parte, como dice el Informe sobre Desarrollo Humano de Naciones Unidas de 1999, a que acuerdos como los ADPIC "fueron firmados antes de que la mayoría de los gobiernos y la gente entendieran el impacto social y económico de las patentes sobre formas de vida. También fueron negociados con muy poca participación de países en desarrollo que ahora están notando el impacto de sus condiciones”42.

La relativa efectividad con la que han conseguido implantarse los ADPIC debe entenderse desde situaciones como los modos de funcionar de la OMC, la justificación de la propiedad intelectual e industrial como generadora de riqueza y desarrollo, la agresiva política de los países ricos en la OMC y mediante tratados bilaterales o la asunción como normal de que la propiedad sea el elemento central en la gestión del conocimiento en las sociedades. Todo ello, sin embargo, enmascara una normativa impuesta en contra de los intereses de muchos países y sus ciudadanos, que genera beneficios solo para los Estados desarrollados, en detrimento de todos los demás, y que ignora muchas otras formas de gestionar la creación y difusión del conocimiento no mercantilizadas.

\section{I Desigualdad en las Negociaciones}

Una parte del contenido normativo recogido en los ADPIC se encuentra ya previsto en tratados anteriores -especialmente los ya mencionados de París y de Berna-, como, por ejemplo, la previsión de derechos exclusivos sobre las obras literarias y artísticas durante un plazo de 50 años p. m. a. (post mortem auctoris, tras la muerte del autor). No obstante, la inclusión de estos elementos en los ADPIC y, por ende, en la OMC, tiene consecuencias importantes: el cumplimiento está sometido a los mecanismos de resolución de conflictos de la oMc, al modo de funcionamiento profundamente desigual de esta, y además la aceptación de los ADPIC resulta obligatoria para cualquier país que quiera formar parte de la Organización. Pero, a su vez, al quedar bajo el paraguas de la OMC, el funcionamiento de los ADPIC debe regirse por ciertos principios rectores, como la "no discriminación", la "protección del medio ambiente" o ser más "beneficioso para los países en desarrollo" 43 , lo cual, como se verá, puede tener consecuencias interpretativas de relevancia.

Si respecto de los derechos de autor y el copyright pueden plantearse las siguientes preguntas: ¿son los derechos de propiedad intelectual beneficiosos para los autores?, ¿incentivan la creación?, en este contexto de normativa internacional parece lícito formular estas preguntas: ¿son los ADPIC beneficios para los países en desarrollo?, ¿genera la propiedad intelectual riqueza global que justifique su existencia?

42 Ibid. Para el Informe sobre el Desarrollo Humano, vid.: http://hdr.undp.org/es/ content/informe-sobre-desarrollo-humano-1999

43 Ver https://www.wto.org 
Parece ser que, "pese a que los ADPIC fueron pregonados como vehículo para el desarrollo económico, la inversión directa extranjera, la transferencia de tecnología y el incremento de acceso a los mercados del mundo desarrollado en agricultura y textiles, no ha sido demostrado que hayan mejorado las condiciones del mundo en desarrollo" ${ }^{44}$. Los efectos negativos que los ADPIC han tenido a corto plazo, en cambio, sí son empíricamente demostrables, y la estructura internacional que enmarca esta normativa -la OMC- impide a los Estados adaptar sus legislaciones nacionales para tratar de adecuar la propiedad intelectual e industrial a sus situaciones particulares, de forma que por lo menos no supusiera un elemento en contra del desarrollo económico de los países más pobres. En los países pobres, el sistema de patentes auspiciado por los ADPIC es puesto en cuestión por la falta de datos empíricos que avalen su efecto incentivo para la innovación, así como por la poca utilidad para los países en desarrollo ${ }^{45}$.

Así pues, los ADPIC han sido justificados por su potencial contribución al desarrollo, a los intereses de los consumidores y de los propietarios de los derechos exclusivos de propiedad intelectual, así como por su efecto incentivo a la creación de obras literarias y artísticas y de inventos, aunque ninguno de estos efectos haya sido empíricamente demostrado. En cambio, parece claro que los ADPIC otorgan a países como EE. UU. una ventaja injusta sobre el resto de los miembros -al fin y al cabo, es el principal poseedor mundial de derechos de propiedad intelectual e industrial-, que les permite "influir sobremanera en el ritmo del progreso industrial y tecnológico de los países industrializados y del tercer mundo" 46 .

Ni siquiera en Japón -país en el que se ha dado un rápido proceso de industrialización y especialización técnica- existen datos empíricos que justifiquen la propiedad intelectual e industrial como motor creativo y de innovación. Los investigadores Mariko Sakakibara y Lee Branstetter se preguntan si la expansión de la esfera de acción de las patentes implica mayor esfuerzo en innovación por parte de las empresas, y para ello analizan el caso japonés y su respuesta a la reforma de la normativa de patentes en 1988. En su estudio, ambos autores concluyen que las empresas japonesas no han "respondido" al cambio en el régimen de patentes, sino que se han adaptado a este, es decir, que ha aumentado el número de reclamaciones por parte de propietarios de patentes, pero no hay "pruebas de un incremento en el esfuerzo de innovación o de resultados en innovación que pueda ser atribuida de forma plausible a la reforma de la normativa de patentes" ${ }^{\prime 47}$. Esta es una conclusión a la que, afirman estos dos autores, han llegado otros investigadores al analizar los

44 Harris. Op. cit., pp. 108-109.

45 Sarkissian, Alfred. Intellectual property rights for developing countries: Lessons from Iran. Technovation. Fife, Scotland, UK: University of St Andrews, 2008, 28, pp. 795-796. ISSN: 0166-4972.

46 Jawara y Kwa. Op. cit., p. 116.

47 Sakakibara, Mariko y Branstetter, Lee. Do stronger patents induce more innovation? Evidence from the 1988 Japanese patent law reforms. En K. E. MAskus (ed.). The WTO, intellectual property rights and the knowledge of economy. Cheltenham: Edward Elgar, 2004, p. 565. ISBN: 9781843762379. 
datos en países con elevados niveles de protección de la propiedad intelectual e industrial, como EE. UU.

$\mathrm{Al}$ margen del discurso oficial o de la propia idea en la que se basa la OMC, los datos permiten poner en cuestión el argumento de que el endurecimiento de las normas de propiedad intelectual e industrial (o su extensión a todos los países del mundo) vaya a incrementar la innovación o a contribuir al desarrollo de los países pobres. En cambio, el estudio de cómo ha funcionado la aplicación de los ADPIC a nivel mundial permite poner de manifiesto que el Acuerdo ha sido utilizado por los países propietarios de bienes inmateriales (patentes y contenido protegido por copyright o derechos de autor, principalmente) como elemento para exigir que las demás naciones adaptaran su legislación de forma que esos mismos países ricos salieran beneficiados.

\subsection{Poder de Negociación de los Estados propietarios}

\subsubsection{Dificultades para adoptar niveles óptimos de protección}

Por todo lo que se ha analizado aquí, se mantiene que los ADPIC no buscan mejorar la situación de los países en los que se aplican y que resulta dudoso, desde el punto de vista empírico, que la propiedad intelectual e industrial sea realmente beneficiosa para incentivar la creación y generar riqueza. El discurso de que esa normativa implica riqueza y beneficios es válido solo para aquellos Estados que generan gran cantidad de este tipo de bienes (países con poderosas industrias farmacéuticas, musicales o cinematográficas), pero es cuestionable para países que, en esencia, son consumidores de este tipo de creaciones.

El consumo por parte de algunos países de gran cantidad de bienes culturales de otros Estados no responde a que la producción cultural del país exportador sea necesariamente mayor o mejor [que] la del país importador. Lo que sí se da es una importante y agresiva operación por parte de las empresas de entretenimiento para extender ciertos bienes culturales -especialmente de EE. UU.- a todos los países. Para ello, por ejemplo, grandes sellos discográficos invierten en artistas locales de otros países, proporcionándoles los recursos materiales y personales para editar y vender un disco, y realizan enormes campañas publicitarias. A cambio, estos artistas locales deben adaptar su música a unos estándares exigidos por la discográfica que permiten exportar ese estilo a otros mercados totalmente diferentes. El éxito comercial (deudor en gran parte de la promoción publicitaria) permite situar a la discográfica en una posición de poder no solo material, sino simbólico frente a otros artistas sin recursos de ese país pobre, cuyas expresiones artísticas originales quedan ocultas a los ojos del gran público. Por ello, cuando se habla de países consumidores, debe entenderse en esta doble vertiente: la de la imposición jurídico-estatal de una normativa que entiende las obras como bien[es] 
comercializable $[\mathrm{s}]$ y la de las agresivas campañas de empresas de entretenimiento extranjeras para colonizar los ámbitos y el imaginario cultural de los países en desarrollo.

En este sentido, no resulta descabellado argumentar -en la lógica comercial de la OMC y los ADPIC- que la propiedad intelectual e industrial debería por lo menos poder adaptarse en cada país a las necesidades que la nación tenga en un momento histórico determinado, en función de su evolución, desarrollo e industrialización. En vez de convertirse en un país altamente desarrollado que produce y exporta filmes y patentes farmacéuticas, a un país pobre puede interesarle tener niveles bajos de protección que le permitan educar a su población a costes menores o proporcionar medicamentos lo más baratos posibles (en forma, por ejemplo, de genéricos fabricados por el mismo Estado); incluso puede interesarle ofrecer una protección por patente de muy corta duración para que sus empresas locales puedan copiarla en un plazo razonable y aplicarla a sus industrias, de forma que la lógica sea que paulatinamente ese país pueda irse incorporando al mercado global de propiedad intelectual e industrial no ya como un mero consumidor, sino como productor y exportador de bienes inmateriales; o incluso aprobar niveles de protección que respeten otras maneras de entender la gestión y la transmisión del conocimiento diferentes a las que propone la normativa internacional actual.

Pero los ADPIC -y sus principales promotores- no han buscado niveles óptimos en función de las necesidades del país, sino aumentar al máximo la protección de propiedad intelectual e industrial porque ello responde a los intereses de las empresas transnacionales que hay detrás, y, por tanto, favorecen de forma directa los intereses comerciales de unos Estados concretos en detrimento de otros. Es más, hay países en desarrollo que se han visto obligados a adoptar estándares de propiedad intelectual e industrial más fuertes que los de los países desarrollados.

Peter Drahos, especialista en derechos de propiedad industrial e intelectual y globalización y uno de los autores que más ha tratado este tema, lo explica de la siguiente manera: "[Los] ADPIC son parte de una estructura en evolución que impacta directamente en la libertad de diseño de todos los países en lo que a derechos de propiedad intelectual e industrial se refiere" ${ }^{38}$. Todos los miembros de la OMC tienen que implementar las obligaciones de los ADPIC mediante su legislación nacional. El Acuerdo permite a un miembro acordar una mayor protección -a nivel interno o en un pacto bilateral con otro Estado-, pero prohíbe expresamente formas de protección menores de las estipuladas por los ADPIC.

Lo que los ADPIC configuran -una forma de entender la protección de las ideas y expresiones artísticas-, pues, es un mínimo satisfactorio para los países exportadores de estos bienes (con predominio de EE. UU., la UE y Japón), pero no para muchos otros Estados en desarrollo, para los cuales resultan obligatorios

48 Drahos, Peter. An alternative framework for the global regulation of intellectual property rights. Austrian Journal of Development Studies. Österreich: Universität Wien, 2005, 1, p. 6. ISSN: 0258-2384. 
unos niveles de protección altamente perjudiciales para sus economías. La OMC y los ADPIC, en este sentido, imponen la protección de la propiedad intelectual e industrial "siendo entendidos esos derechos como 'derechos privados" 49 por encima de su adecuación a ámbitos de gran relevancia social, como los recursos farmacéuticos o la educación de los ciudadanos.

Que los derechos de propiedad intelectual e industrial tal y como están regulados en los ADPIC no resultan óptimos para todos los países es evidente. Hay una estrecha identificación de este tipo de derechos con el nivel económico de un Estado, y son los países ricos los que intentan mantener los bienes inmateriales como elemento comercial-mercancía-, por encima de su configuración como bien necesario para determinadas sociedades. Los países pobres, en cambio, intentan acceder a ese conocimiento (mercantilizado) al menor precio posible, por lo que tienen interés en una baja protección legal.

Bajo la mercantilización del conocimiento humano subyace la idea de que el proceso
de privatización de lo inmaterial o lo intelectual pretende mantener el statu quo entre
el 'norte' y el 'sur' (entre países desarrollados y países pobres). En este sentido, la priva-
tización de los bienes culturales y creaciones intelectuales no respondería solo al interés
de configurar como mercancía esos bienes para poder comercializar con ellos y obtener
un beneficio económico, sino que todo el entramado internacional tendría como tras-
fondo evitar que una excesiva difusión de elementos de desarrollo tecnológico y cultural
privaran al 'norte' de algunas de sus ventajas que le garantizan dominio sobre el 'sur'

Por tanto, que se consiguiera incluir esta regulación de los derechos de propiedad intelectual e industrial en el marco de la OMC -con la consiguiente exigibilidad a todos sus miembros, casi todos los países del mundo- resulta un logro más que notable por parte de los países exportadores de estos bienes. Este es un logro que se explica, en gran parte, por el modo de funcionar de la omc y las presiones, los tratos y las negociaciones internacionales, más que con el hecho de que el Acuerdo sea beneficioso para los países en desarrollo.

De ello resulta la clara disparidad entre países ricos y países pobres en lo que a los ADPIC se refiere. Los primeros pueden tratar de conseguir mayor protección de los derechos de propiedad intelectual e industrial, pues ello tiende a beneficiar sus intereses comerciales; mantienen por tanto una cierta soberanía y pueden realizar las modificaciones legales que les benefician sin contravenir la normativa internacional. En cambio, los países pobres parten con clara desventaja, puesto que el marco normativo ya les es perjudicial -sobre todo por los ADPIC- y cualquier cambio nunca puede implicar una menor protección, lo que significa que su soberanía como Estados se ve claramente mermada ${ }^{51}$.

51 Iglesias Prada, Juan Luis (coord.). Disposiciones generales y principios básicos 
La situación resultante es la de una normativa internacional que se aplica de manera obligada por medio de la normativa nacional de cada Estado, independientemente de los intereses domésticos. Al ser una legislación que favorece los intereses de los países ricos, no proporciona los mismos beneficios, pues los ingresos generalmente fluyen desde los Estados pobres a los propietarios de los derechos de propiedad intelectual e industrial ${ }^{52}$. El impacto resulta evidente en los países pobres: "[...] retraso en el desarrollo tecnológico, masiva transferencia de riqueza fuera de esos países y otros costes sociales, como la falta de acceso a medicinas" 53 .

Parece poco probable, por ejemplo, que a un país como Kenia le pueda interesar un nivel de protección por copyright o derechos de autor de libros y publicaciones similar al de EE. Uu. o la UE. Mientras que, en estos dos últimos, la venta de libros se ha mercantilizado hasta el punto de que el éxito comercial puede quedar muy lejos de la calidad o interés literario, en Kenia la idea de propiedad sobre lo escrito puede resultar culturalmente chocante, pues nos encontramos ante un país en el que 'la mayoría de la gente vive una vida comunitaria en la que compartir lo que uno tiene es una virtud. Esta característica molesta a los propietarios de derechos, ya que Kenia es un importador neto $[\ldots]^{54}$. A pesar de ello, Kenia se ve obligado a tener una legislación pensada para países como EE. uU., lo cual provoca que, obviamente, el nivel de piratería en el país africano sea alto.

La armonización que han supuesto los ADPIC puede llegar a tener efectos importantes sobre ámbitos como la salud o la educación de los ciudadanos. Como se ha dicho, una menor protección de la propiedad intelectual o industrial puede deberse al intento de búsqueda de un país del nivel óptimo en función de las necesidades de sus ciudadanos ${ }^{55}$. Y es que los ADPIC, tan bien configurados para obtener niveles altos de protección, no ofrecen mecanismos para garantizar niveles mínimos de acceso a bienes fundamentales que permitan el correcto desarrollo de sociedades en situaciones de precariedad.

en el "Acuerdo sobre los Aspectos de los Derechos de Propiedad Intelectual relacionados con el Comercio" (adpic). En J. L. Iglesias Prada (coord.). Los derechos de propiedad intelectual en la Organización Mundial del Comercio. El Acuerdo sobre los Aspectos de los Derechos de Propiedad Intelectual relacionados con el Comercio. Madrid: Instituto de Derecho y Ética Industrial, 1997, pp. 117-132. ISBN: 84-89246-07-6.

52 Harris. Op. cit.

53 Ibid., p. 101.

54 Olaka, Musam \& Adkins, Denice. Exploring copyright knowledge in relation to experience and education level among academic librarians in Kenya. The International Information \& Library Review. UK: Taylor \& Francis, 2012, pp. 40-51 (p. 41). ISsN: $1057-2317$.

55 Nicholson, Denise. Intellectual property: Benefit or burden for Africa? IFLA Journal. UK: Sage Publications, 2006, 32(4), pp. 310-324. Issn: 03400352. 


\subsubsection{El blindaje de la normativa internacional y las estrategias bilaterales}

Como se vio, en el ámbito de la omc, los tratados de libre comercio -bilaterales o regionales- son un elemento importante en la forma de hacer política de la Organización. Para EE. UU., por ejemplo, ha sido un instrumento efectivo para tratar de presionar a distintos países a abandonar el grupo G20 en el marco negociador de las Conferencias Ministeriales. También en el ámbito de los ADPIC, los tratados bilaterales suponen un elemento importante por el efecto de la denominada cláusula de nación más favorecida (NMF), prevista en el artículo 4 de los ADPIC ${ }^{56}$.

En ocasiones, dos Estados pueden negociar de forma bilateral un tratado que prevea niveles distintos de protección de la propiedad intelectual e industrial que los previstos en los ADPIC. Estos tratados bilaterales reciben el nombre de ADPIC Plus, porque siempre implican un mayor nivel de protección que el previsto en el Acuerdo. Dada la dificultad de aprobar ciertas medidas en el marco de la OMC (que funciona por unanimidad), este tipo de tratados se han mostrado efectivos para aquellos países que desean aumentar los niveles de protección de propiedad intelectual e industrial alrededor del mundo y que son conscientes de la dificultad de conseguir convencer a todos los países miembros.

Es decir, estos tratados resultan especialmente útiles para los países desarrollados - pues favorecen sus intereses económicos- y especialmente perjudiciales para los países interesados en niveles bajos de protección por la cláusula NMF. Esta cláusula determina que, si un país miembro de los ADPIC acuerda con otro algún tipo de modificación de la normativa de propiedad intelectual o industrial-que, recuérdese, siempre deberá implicar igual o mayor protección que la prevista en los ADPIC-, ambos deberán automáticamente ofrecer esos niveles de protección al resto de los países miembros.

La cláusula NMF aparecía ya en el GATT y es común en otros tratados multilaterales. En el caso de los ADPIC, resulta de especial relevancia porque supone dificultar todavía más la adaptación por parte de los países de los niveles de protección a sus necesidades. Es decir, si, por ejemplo, EE. UU. acuerda un determinado nivel de protección mediante un tratado bilateral con otro Estado miembro de la OMC, podrá exigírsele a ese país que aplique ese nivel de protección al resto de los países miembros. De esta forma, por una suerte de efecto dominó, ese nivel de protección acordado con EE. UU. se extiende. El problema está en que, mientras que al país norteamericano le interesa que esos altos niveles de protección sean aplicados a todos los países, al país con el que ha firmado el tratado bilateral puede interesarle solo con EE. UU., pero no con el resto. Y, a su vez, el resto de los países pueden no desear que se extiendan esos niveles de protección. La consecuencia es que las

56 El artículo 4 de los ADpIC reza como sigue: "Con respecto a la protección de la propiedad intelectual, toda ventaja, favor, privilegio o inmunidad que conceda un Miembro a los nacionales de cualquier otro país se otorgará inmediatamente y sin condiciones a los nacionales de todos los demás Miembros [...]". 
paulatinas modificaciones de la normativa de propiedad intelectual e industrial tienden a implicar un aumento de los estándares de protección, con el consiguiente beneficio para los países ricos y perjuicio para los pobres.

Así pues, el principal objetivo -y consecuencia- de la cláusula de NMF ha sido el aumento de los "estándares de protección de la propiedad intelectual e industrial mediante las negociaciones de los Tratados de Libre Comercio" 57 . Esta uniformización internacional de los niveles de protección favorece principalmente a países como EE. UU., que son conscientes de la dificultad de aumentar las exigencias de propiedad intelectual e industrial en el marco de la OMC, que exige unanimidad. Para ello, los TLC (junto con la cláusula de NMF) se muestran como un instrumento más útil para alcanzar sus objetivos ${ }^{58}$. En la práctica, la NMF implica que los ADPIC solo pueden ir a más, aun cuando este enfoque es contrario a los objetivos y finalidades del Acuerdo sobre los ADPIC y a las leyes de propiedad intelectual.

Todo ello explica el interés de algunos países - principalmente países ricos- en que determinados temas se incluyan en el ámbito decisorio de la oMc, sustrayendo la capacidad de cada Estado de determinar qué régimen de propiedad sobre los bienes inmateriales resulta más adecuado a sus intereses. Negociar en el ámbito de la OMC implica que en la práctica se aplican los "modos de hacer" política de esta Organización, en la que el poder negociador es profundamente desigual, y en caso de dificultad para aprobar nuevas medidas, los tratados bilaterales junto con la cláusula de NMF resultan realmente eficaces ${ }^{59}$.

\section{CONCLUSIONES}

La normativa internacional -y, por tanto, también en última instancia la nacionalrespecto a propiedad intelectual está excesivamente encaminada a la apropiación de conocimiento más que a su difusión. En este sentido, ya el anterior régimen internacional -con el destacado papel de la ompi y los Convenios de Berna y de París- protegía una concepción propietaria del conocimiento y las expresiones artísticas e intelectuales. El nuevo régimen, fundado con la OMC y los ADPIC, minimiza el carácter multilateral característico de la OMPI para imponer una normativa armonizada en todo el mundo que a la postre beneficia a muy pocos Estados en detrimento de muchos otros ${ }^{60}$. Además, los mecanismos de funcionamiento de la oMC distan de ser democráticos o transparentes, lo que resta legitimidad a un organismo cuyo interés principal debería ser favorecer el comercio a nivel internacional y no en favor de unos determinados Estados solamente.

El sistema de derechos fuertes de propiedad intelectual e industrial -con mecanismos de imposición de unos Estados a otros mediante prácticas poco transparentes

57 Frankel. Op. cit., p. 181.

58 Drahos. Op. cit., p. 6.

59 Jawara y Kwa. Op. cit., p. 119.

60 Drahos. Op. cit. 
y sanciones internacionales- contribuye a mantener un tipo de relación comercial entre países ricos y pobres que beneficia a los primeros. Los países subdesarrollados son principalmente importadores de toda clase de bienes inmateriales, mientras que los países más desarrollados son exportadores.

[El Acuerdo de los] ADPIC fue diseñado para reforzar y armonizar a nivel mundial la protección de los derechos de propiedad intelectual e industrial [...] [y] fue un éxito al proporcionar dichos estándares, con el resultado de que mayores ingresos van a parar a los países exportadores de propiedad intelectual e industrial, particularmente a los Estados Unidos ${ }^{61}$.

Ello permite entender por qué la propiedad intelectual se ha visto ampliamente infringida en algunos países en desarrollo, pues los estándares impuestos resultan poco o nada útiles para sus intereses comerciales y para su población.

El actual régimen internacional en esta materia, reflejo de la configuración comercial mundial, permite que la propiedad intelectual e industrial sea un negocio siempre que haya países dispuestos - u obligados- a comprar esos productos ${ }^{62}$. Pero el alto coste para esos Estados y la explotación de sus propios recursos implica que los países pobres difícilmente logren "ascender" y convertirse en uno de los países exportadores. Es significativo que el propio Banco Mundial reconociera en un informe de 2002 que, mientras que los países desarrollados resultan beneficiados por la protección que suponen los ADPIC, los países pobres son perdedores netos ${ }^{63}$. Un régimen de propiedad intelectual e industrial más justo y más equitativo podría redistribuir las cargas y repartir los beneficios, pero ello implicaría, por parte de los países ricos, un sacrificio en sus balances comerciales que no parecen dispuestos a aceptar.

\section{BIBLIOGRAFÍA}

Capella Hernández, Juan Ramón. Entrada en la barbarie. Madrid: Trotta, 2007. ISBN: 978-84-8164-779-2.

Capella Hernández, Juan Ramón. Fruta prohibida. Una aproximación históricoteorética al estudio del derecho y del Estado. Madrid: Trotta, 2008. ISBN: 97884-9879-013-9.

Díez De Velasco, Manuel. Las organizaciones internacionales. 14. a ed. Madrid: Tecnos, 2006. ISBN: 9788430942978.

61 Harris. Op. cit., p. 101.

62 Panagariya, Arvind. trips and the wto: An uneasy marriage. En K. Maskus (ed.) The WTO, intellectual property rights and the knowledge of economy. Cheltenham: Edward Elgar, 2004. ISBN: 9781843762379.

63 World Bank. Global economic prospects and the developing countries 2002: Making trade work for the world's poor. Washington: World Bank, p. 133, 2001. 
Dinwoodie, Graeme y Dreyfuss, Rochelle. A neofederalist vision of trips. The resilience of the International Intellectual Property Regime. New York: Oxford University Press, 2012. IsBN: 9780195304619.

Drahos, Peter. Information feudalism in the information society. The Information Society. U. S. A.: Taylor and Francis, 1995, 11(3), pp. 209-222. ISSN: 0197-2243.

Drahos, Peter. When the weak bargain with the strong: Negotiations in the wто. International Negotiation. Leiden, The Netherlands: Brill, 2003, 8(1), pp. 77-109. ISSN: 1382-340X.

Drahos, Peter. An alternative framework for the global regulation of intellectual property rights. Austrian Journal of Development Studies. Österreich: Universität Wien, 2005, 1, p. 6. ISSN: 0258-2384.

Drahos, Peter. When cosmology meets property: Indigenous people's innovation and intellectual property. Prometheus: Critical Studies in Innovation. UK: Taylor and Francis, 2011, 29(3), pp. 233-252. ISSN: 0810-9028.

Frankel, Susan. Legitimidad y finalidad de los capítulos de propiedad intelectual en los tratados de libre comercio (TLC). Revista La Propiedad Inmaterial. Bogotá: Universidad Externado de Colombia, 2011, (15), pp. 169-187. IssN: 1657-1959.

HarRIs, Donald. TRIPS' rebound: An historical analysis of how the TRIPS Agreement can ricochet back against the United States. Northwestern Journal of International Law \& Business. Chicago: Northwestern University, 2004, 25(1), pp. 99-163. ISSN: 0196-3228.

Iglesias Prada, Juan Luis. Disposiciones generales y principios básicos en el "Acuerdo sobre los Aspectos de los Derechos de Propiedad Intelectual relacionados con el Comercio" (adpic). En J. L. Iglesias Prada (coord.). Los derechos de propiedad intelectual en la Organización Mundial del Comercio. El Acuerdo sobre los Aspectos de los Derechos de Propiedad Intelectual relacionados con el Comercio. Madrid: Instituto de Derecho y Ética Industrial, 1997, pp. 117-132. ISBN: 84-89246-07-6.

Jawara, Fatoumata y Kwa, Aileen. Tras las bambalinas de la OMC. La cruda realidad del comercio internacional. Barcelona: Intermón Oxfam Editorial, 2005. ISBN: 9788484523246.

Malbon, Justin y Lawson, Charles. Interpreting and implementing the TRIPS Agreement. Is it fair? Cheltenham: Edward Elgar, 2008. IsBN: 9781847201447.

Maskus, KeIth. The WTO, intellectual property rights and the knowledge of economy. Cheltenham: Edward Elgar, 2004. IsBN: 9781843762379.

Maskus, Кегтн. Regulatory standards in the wто: Comparing intellectual property rights with competition policy, environmental protection, and core labor standards. In K. MasKus (ed.). The WTO, intellectual property rights and the knowledge of economy. Cheltenham, Edward Elgar, 2004. IsBN: 9781843762379. 
Mitsui, Toru. Copyright and music in Japan: A forced grafting and its consequences. En S. Frith (ed.). Music and copyright. Edinburgh: Edinburgh University Press, 1993. ISBN: 0748604812.

Nicholson, Denise. Intellectual property: Benefit or burden for Africa? IFLA Journal. UK: Sage Publications, 2006, 32(4), pp. 310-324. IssN: 03400352.

Olaka, Musam \& Adkins, Denice. Exploring copyright knowledge in relation to experience and education level among academic librarians in Kenya. The International Information \& Library Review. UK: Taylor \& Francis, 2012, pp. 40-51. ISSN: 1057-2317.

Panagariya, Arvind. trips and the wto: An uneasy marriage. En K. Maskus (ed.). The WTO, intellectual property rights and the knowledge of economy. Cheltenham: Edward Elgar, 2004. ISBN: 9781843762379.

Ramos Toledano, Joan. Bilateralidad, pérdida de soberanía y secretismo. En mientrastanto.e. Barcelona: Fundación Giulia Adinolfi-Manuel Sacristán. 2016, (146). ISSN (versión digital): 2014-7317. Disponible en http://www.mientrastanto.org/boletin-146/notas/bilateralidad-perdida-de-soberania-y-secretismo

Sakakibara, Mariko \& Branstetter, Lee. Do stronger patents induce more innovation? Evidence from the 1988 Japanese patent law reforms. En K. MasKUS (ed.). The WTO, intellectual property rights and the knowledge of economy. Cheltenham: Edward Elgar, 2004. IsBN: 9781843762379.

SARKISSIAN, AlfRED. Intellectual property rights for developing countries: Lessons from Iran. Technovation. Fife, Scotland, UK: University of St Andrews, 2008, 28, pp. 786-798. ISSN: 0166-4972.

Sell, Susan. Life after trips - Aggression and opposition. En K. Maskus (ed.). The WTO, intellectual property rights and the knowledge of economy. Cheltenham: Edward Elgar. 2004, pp. 72-119. ISBN: 9781843762379.

Smiers, Joost. Un mundo sin copyright. Artes y medios en la globalización. Barcelona: Gedisa, 2006. IsBN: 978-84-9784-052-1.

The World Bank. Global economic prospects and the developing countries 2002: Making trade work for the world's poor. Washington: World Bank, 2001. 